Revista Brasileira de Agricultura Irrigada v.10, nº.3, p. 687 - 694, 2016

ISSN 1982-7679 (On-line)

Fortaleza, CE, INOVAGRI - http://www.inovagri.org.br

DOI: $10.7127 /$ rbai.v10n300410

Protocolo 410.16 - 04/03/2016 Aprovado em 20/06/2016

\title{
TEORES DE MICRONUTRIENTES EM PLANTAS DE SORGO FORRAGEIRO IRRIGADAS COM EFLUENTE SALINO DE PISCICULTURA
}

\author{
Miguel Julio Machado Guimarães ${ }^{1}$, Welson Lima Simões ${ }^{2}$, Alessandra Monteiro Salviano², \\ Lilia Gomes Willadino ${ }^{3}$, Iug Lopes ${ }^{4}$, Kelliane de Souza Galvão ${ }^{5}$
}

\begin{abstract}
RESUMO
O conhecimento do estado nutricional de uma cultura em condições salinas é essencial para definir qual o manejo mais adequado para o seu cultivo. Com isto, objetivou-se com o presente estudo avaliar o estado nutricional de micronutrientes catiônicos de variedades de sorgo forrageiro irrigadas com efluente salino de piscicultura. O estudo foi implantado no município de Petrolina/PE no ano de 2013, em Argissolo Vermelho Amarelo. O delineamento experimental utilizado foi blocos ao acaso, com quatro repetições. Os tratamentos foram dispostos em parcelas subdivididas, sendo as parcelas quatro frações de lixiviação: 0; 5; 10 e $15 \%$, com efluente salino $\left(2,57 \mathrm{dS} \mathrm{\textrm {m } ^ { - 1 }}\right)$ proveniente de piscicultura e as subparcelas três variedades de sorgo forrageiro: Volumax, F305 e Sudão. A colheita foi realizada quando os grãos da porção central da panícula apresentaram aspecto pastoso a farináceo. Foram coletadas amostras do limbo foliar para determinação dos teores cobre, ferro, manganês e zinco por espectrofotometria de absorção atômica. Verificou-se que a aplicação de frações de lixiviação proporcionou uma redução nos teores de ferro, manganês e zinco, e um aumento no teor de cobre nos tecidos foliares de sorgo forrageiro.
\end{abstract}

Palavras-chave: salinidade, Sorghum bicolor (L.) Moench, nutrição mineral.

\section{IRRIGATION WITH SALINE EFFLUENT AQUACULTURE OF MODIFYING THE NUTRITIONAL STATUS IN FORAGE SORGHUM PLANTS}

\footnotetext{
ABSTRACT

Knowledge of the nutritional status of a culture in saline conditions is essential to define the most appropriate management for its cultivation. With this, the aim of the present study was to

${ }^{1}$ Universidade Federal Rural de Pernambuco, Departamento de Engenharia Agrícola, Recife-PE, E-mail: mjmguimaraes@hotmail.com.

2 Embrapa Semiárido, Petrolina-PE, E-mail:welson.simoes@embrapa.br; alessandra.salviano@embrapa.br.

${ }^{3}$ Universidade Federal Rural de Pernambuco, Departamento de Biologia, Recife-PE, E-mail: willadino.lilia@gmail.com.

${ }^{4}$ Universidade Federal do Vale do São Francisco, Juazeiro-BA, E-mail:iuglopes@hotmail.com.

${ }^{5}$ Universidade de Pernambuco, Petrolina-PE, E-mail: kellianesg@gmail.com
} 
evaluate the nutritional status of cationic micronutrient varieties of sorghum irrigated with saline effluent from fish farming. The study was implemented in the city of Petrolina-PE in 2013 in Alfissol. The experimental design was a randomized block design with four replications. The treatments were arranged in split plots, with the four installments leaching fractions: 0 ; 5; 10 and 15\% with saline effluent (2.57 dS m-1) from fish and subplots three varieties of sorghum:. Volumax, F305 and Sudan The crop was harvested when the grains of the central portion of the panicle showed aspect doughy the chalky. the leaf blade samples were collected to determine levels of copper, iron, manganese and zinc by atomic absorption spectrophotometry. It has been found that the application of leaching fractions afforded a reduction in the levels of iron, manganese and zinc, and an increase in copper content in the leaves of sorghum.

Keywords: salinity, Sorghum bicolor (L.) Moench, mineral nutrition,

\section{INTRODUÇÃO}

A deficiência de micronutrientes tem sido um fator limitante à produtividade, variando conforme o tipo da cultura e do solo, podendo resultar desde uma pequena redução até a perda total da produção (CARMO et al., 2012; SANTI et al., 2005). A atenção nestes elementos para forrageiras está no fato que as formulações minerais utilizadas, na maioria das vezes, só fornecerem os macronutrientes mais importantes (N, P, K e S) não havendo suplementação adequada de micronutrientes.

Em sistemas que utilizam água salina para irrigação, os elevados teores de sais podem não interferir na absorção de elementos tóxicos e dos nutrientes essenciais (GURGEL et al. 2008; NEVES et al., 2009). No entanto, esse efeito da salinidade sobre a composição mineral das plantas varia com a espécie avaliada e está relacionado com mecanismos de tolerância à salinidade (DIAS; BLANCO, 2010).

Em ambientes salinos, a solubilidade dos micronutrientes $\mathrm{Fe}, \mathrm{Cu}, \mathrm{Mn}$ e $\mathrm{Zn}$ é baixa, e seu efeito pode resultar na deficiência desses elementos às plantas cultivadas nestes solos (GRATTAN; GRIEVE, 1999). Nestas condições, o uso de frações de lixiviação é uma estratégia que vêm sendo utilizada no manejo da irrigação, a qual constitui-se de aplicar uma lâmina adicional de água juntamente com a lâmina necessária para a cultura, com o objetivo de lixiviar os sais presentes na rizosfera. Com os sais fora da zona radicular, consegue-se manter a salinidade em um nível específico que seja favorável para o desenvolvimento da cultura a ser cultivada.

Nos últimos anos o cultivo de sorgo forrageiro vem ganhando grande destaque em regiões com baixa disponibilidade de água e fertilidade do solo devido à facilidade de cultivo, rapidez no estabelecimento e crescimento, além de um bom valor nutricional e da alta produção de forragem (BOTELHO et al., 2010; SANTOS et al., 2013).

Com isto, o presente estudo teve o objetivo de avaliar a influência do uso de irrigação com efluente salino de piscicultura nos teores de micronutrientes em plantas de sorgo forrageiro.

\section{MATERIAL E MÉTODOS}

O estudo foi conduzido no ano de 2013, no Campo Experimental Caatinga, pertencente à Embrapa Semiárido, em Petrolina - PE, na região do Submédio São Francisco (latitude $9^{\circ}$ 8' 8,9" S, longitude $40^{\circ} 18^{\prime} 33,6$ ”'O, altitude $\left.373 \mathrm{~m}\right)$. O clima da região é classificado, segundo Köppen, como semiárido do tipo BSwh'. As chuvas concentram-se entre os meses de novembro e abril, com precipitação média anual em torno de $400 \mathrm{~mm}$, irregularmente distribuída. Durante o período do estudo a umidade relativa do ar média foi de 63,86\% 

EFLUENTE SALINO DE PISCICULTURA

e a temperatura média em torno de $25,46^{\circ} \mathrm{C}$, com evapotranspiração máxima de $6,97 \mathrm{~m}$ $\mathrm{dia}^{-1}$, tendo uma média de $5,85 \mathrm{~mm} \mathrm{dia}^{-1}$. Os principais eventos de precipitação se concentraram nos dez primeiros dias após o plantio (DAP) e aos 74 DAP, totalizando $32,7 \mathrm{~mm}$ ao final do ciclo.
O solo da área experimental foi classificado como Argissolo Vermelho Amarelo (EMBRAPA, 2013) situado em um relevo plano, apresentando textura média. Suas características químicas e físicas podem ser observadas na Tabela 1.

Tabela 1. Características químicas e físicas e granulometria do solo da área experimental.

\begin{tabular}{|c|c|c|c|c|c|c|c|c|c|c|c|c|c|}
\hline \multirow{2}{*}{$\begin{array}{c}\text { Camada } \\
(\mathrm{cm})\end{array}$} & \multirow{2}{*}{$\begin{array}{c}\mathrm{CE} \\
\mathrm{dS} \mathrm{cm}{ }^{-1}\end{array}$} & \multirow{2}{*}{$\begin{array}{l}\mathrm{pH} \\
-\end{array}$} & \multirow{2}{*}{$\begin{array}{l}\text { M.O. } \\
\text { g kg-1 }^{-1}\end{array}$} & \multirow{2}{*}{$\begin{array}{c}\mathrm{P} \\
\mathrm{mg} \mathrm{dm}^{-3}\end{array}$} & K & $\mathrm{Na}$ & $\mathrm{Ca}$ & $\mathrm{Mg}$ & $\mathrm{Al}$ & $\mathrm{H}+\mathrm{Al}$ & SB & CTC & \multirow{2}{*}{$\begin{array}{l}\mathrm{V} \\
\%\end{array}$} \\
\hline & & & & & \multicolumn{8}{|c|}{$\mathrm{cmol}_{\mathrm{c}} \mathrm{dm}^{-3}$} & \\
\hline $0-10$ & 1,64 & 5,5 & 7,7 & 15,65 & 0,65 & 0,80 & 2,8 & 1,50 & 0,00 & 2,1 & 5,8 & 7,8 & 73,4 \\
\hline $10-20$ & 1,99 & 5,7 & 5,7 & 14,25 & 0,55 & 0,65 & 1,9 & 1,30 & 0,00 & 2,7 & 4,4 & 7,1 & 61,8 \\
\hline $20-45$ & 2,91 & 7,4 & 6,3 & 3,60 & 2,05 & 1,50 & 1,8 & 1,40 & 0,00 & 3,7 & 6,8 & 10,4 & 64,7 \\
\hline \multirow{2}{*}{$\begin{array}{c}\text { Camada } \\
\text { (cm) }\end{array}$} & \multicolumn{4}{|c|}{ Densidade $\left(\mathrm{kg} \mathrm{dm}^{-3}\right)$} & \multirow{2}{*}{\multicolumn{3}{|c|}{$\begin{array}{c}\text { Porosidade } \\
\text { Total (\%) }\end{array}$}} & \multicolumn{6}{|c|}{ Granulometria $\left(\mathrm{g} \mathrm{kg}^{-1}\right)$} \\
\hline & \multicolumn{2}{|c|}{ Solo } & \multicolumn{2}{|c|}{ Partícula } & & & & \multicolumn{2}{|c|}{ Areia } & \multicolumn{2}{|l|}{ Silte } & \multicolumn{2}{|c|}{ Argila } \\
\hline $0-10$ & \multicolumn{2}{|l|}{1,46} & \multicolumn{2}{|c|}{2,59} & \multicolumn{3}{|c|}{43,86} & \multicolumn{2}{|c|}{729,4} & 182,9 & & \multicolumn{2}{|c|}{87,7} \\
\hline $10-20$ & \multicolumn{2}{|l|}{1,46} & \multicolumn{2}{|c|}{2,51} & \multicolumn{3}{|c|}{41,74} & \multicolumn{2}{|c|}{789,8} & 116,9 & & \multicolumn{2}{|c|}{93,3} \\
\hline $20-45$ & \multicolumn{2}{|l|}{1,37} & \multicolumn{2}{|c|}{2,52} & \multicolumn{3}{|c|}{45,58} & \multicolumn{2}{|c|}{613,2} & 178,1 & & \multicolumn{2}{|c|}{208,7} \\
\hline
\end{tabular}

$\mathrm{CE}=$ condutividade elétrica do extrato de saturação; $\mathrm{M}, \mathrm{O}$,= matéria orgânica; $\mathrm{P}=$ fósforo disponível extraído por Mehlich $^{-1} ; \mathrm{Ca}=$ cálcio trocável; $\mathrm{Mg}=$ magnésio trocável; $\mathrm{Na}=$ sódio trocável; $\mathrm{K}=$ potássio trocável; Al: acidez trocável; CTC= capacidade de troca de cátions à $\mathrm{pH}$ 7,0; V=saturação por bases; pH determinado em água na proporção de 1:2,5

A área foi preparada conforme necessidades da cultura, realizando-se uma aração e gradagem. A adubação de fundação foi realizada com base na análise de solo (Tabela 1), sendo aplicados $30 \mathrm{~kg}$ ha ${ }^{-1}$ de nitrogênio $(\mathrm{N}), 60 \mathrm{~kg} \mathrm{ha}^{-1}$ de fósforo $\left(\mathrm{P}_{2} \mathrm{O}_{5}\right)$ e $20 \mathrm{~kg} \mathrm{ha}^{-1}$ de potássio $\left(\mathrm{K}_{2} \mathrm{O}\right)$, tendo como fontes ureia, superfosfato simples e cloreto de potássio (CAVALCANTI et al., 2008). A semeadura foi realizada no mês de abril/2013, utilizando-se 10 sementes por metro linear, tendo a emergência ocorrido aos 7 DAP

Aos 30 DAP foi realizada uma adubação nitrogenada de cobertura com 30 $\mathrm{kg} \mathrm{ha}^{-1}$ utilizando-se ureia como fonte do nutriente.

Foi adotado o delineamento experimental em blocos ao acaso, com quatro blocos, em parcelas subdivididas, compostas por três variedades de sorgo forrageiro: Volumax, F305 e Sudão e quatro frações de lixiviação (0; 5; 10 e 15\%,) para irrigação com efluente salino de piscicultura. Os mesmos foram dispostos em parcelas subdivididas com quatro blocos, sendo as parcelas compostas pelas frações de lixiviação e as subparcelas pelas por variedades. Cada unidade experimental (subparcela) foi formada por cinco fileiras de cinco metros de comprimento, espaçadas em 0,5m, perfazendo uma área de $12,5 \mathrm{~m}^{2}$. A parcela útil foi composta pelas três fileiras centrais, eliminando os metros iniciais e finais de cada fileira, totalizando $4,5 \mathrm{~m}^{2}$.

As irrigações foram realizadas, diariamente, por gotejamento superficial por meio de tubo gotejador com emissores com vazão de $1,6 \mathrm{~L} \mathrm{~h}^{-1}$, diâmetro nominal (DN) de $16 \mathrm{~mm}$, espaçados 0,30 m entre si. O sistema de irrigação era ligado aos tanques de piscicultura com capacidade para $5 \mathrm{~m}^{3}$, contento tilápia preta com densidade populacional de 50 peixes por $\mathrm{m}^{3}$. No manejo dos tanques, cerca de $50 \%$ do seu volume total era, diariamente, substituído e bombeado para o tanque de armazenamento, para ser usada na irrigação. A condutividade elétrica da água 
(CEa) dos efluentes da piscicultura foi monitorada semanalmente com o auxílio de um condutivímetro digital portátil, apresentando média de 2,57 $( \pm 0,2)$ $\mathrm{dS} \mathrm{m}^{-1}$.
As características químicas do efluente da piscicultura utilizado na irrigação foram determinadas, semanalmente, durante o experimento, sendo as médias apresentadas na Tabela 2.

Tabela 2. Características químicas da água de irrigação proveniente de tanques de piscicultura.

$$
\begin{array}{llllllll}
\mathrm{Ca}^{2+} & \mathrm{Mg}^{2+} & \mathrm{Na}^{+} & \mathrm{K}^{+} & \mathrm{Cl}^{-} & \mathrm{pH} & \mathrm{CEa} & \text { Dureza }
\end{array}
$$

\begin{tabular}{ccccccccc}
\hline \multicolumn{4}{c}{$\mathrm{mmol}_{\mathrm{C}} \mathrm{L}^{-1}$} & \multicolumn{3}{c}{$\mathrm{dS} \mathrm{m}^{-1}$} & $\mathrm{mg} \mathrm{L}^{-1} \mathrm{de} \mathrm{CaCO}_{3}$ \\
\hline 12,6 & 7,7 & 7,2 & 0,34 & 35,2 & 8,19 & 2,57 & 50,75 & 2,26 \\
$( \pm 1,1)$ & $( \pm 0,9)$ & $( \pm 1,2)$ & $( \pm 0,06)$ & $( \pm 5,1)$ & $( \pm 0,27)$ & $( \pm 0,2)$ & $( \pm 5,4)$ & $( \pm 0,4)$ \\
\hline
\end{tabular}

$\mathrm{CEa}=$ condutividade elétrica a $25^{\circ} \mathrm{C}$; $\mathrm{Ca}=$ cálcio; $\mathrm{Mg}=$ magnésio; $\mathrm{Na}=$ sódio; $\mathrm{K}=$ potássio; $\mathrm{Cl}=$ cloreto; $\mathrm{RAS}=$ relação de adsorção de sódio.

As lâminas de água aplicadas por irrigação, para cada fração de lixiviação, foram calculadas de acordo com a evapotranspiração da cultura $\left(\mathrm{ET}_{\mathrm{o}} * \mathrm{~K}_{\mathrm{c}} * \mathrm{~K}_{\mathrm{l}}\right)$ medida no período entre as irrigações, de acordo com a eficiência de aplicação de água e o coeficiente de irrigação localizada $\left(\mathrm{K}_{\mathrm{l}}\right)$, conforme a Equação (1).

$$
\mathrm{Li}=\frac{(\mathrm{ETo} * \mathrm{Kc} * \mathrm{Kl})-\mathrm{P}}{\mathrm{Ef}} *(1+\mathrm{FL})
$$

em que:

Li - Lâmina de irrigação, mm; ETo Evapotranspiração medida no período, mm; Kc - Coeficiente de cultivo da cultura; $\mathrm{Kl}$ Coeficiente de localização; P - Precipitação medida no período, mm; Ef - Eficiência do sistema de irrigação, 0,9; FL - Fração de lixiviação aplicada, decimal.

Os tratos culturais constituíram de uma capina manual aos 30 DAP e aplicação preventiva de inseticida sistêmico e de contato, do grupo químico metilcarbamato de oxima, contra Lagarta-docartucho (Spodoptera frugiperda) aos 40 e 60 DAP.

A colheita foi realizada no mês de julho, aos 93 DAP, quando os grãos da porção central da panícula apresentaram aspecto pastoso a farináceo. Na ocasião, foram coletadas amostras do limbo foliar e colocadas para secar em estufa a $60^{\circ} \mathrm{C}$ até obter peso constante, sendo pesadas para determinação da massa seca. Em seguida o material foi triturado em moinho tipo Willey e submetido à digestão nítricoperclórica para determinação dos teores dos micronutrientes cobre $(\mathrm{Cu})$, zinco $(\mathrm{Zn})$, ferro (Fe) e manganês (Mn) por espectrofotometria de absorção atômica no modo chama, utilizando-se ar-acetileno (EMBRAPA, 2011).

Os dados obtidos foram submetidos à análise de variância (ANOVA) utilizandose o programa Sisvar 5.0. O efeito das frações de lixiviação na absorção de cada nutriente foi avaliado por meio da análise de regressão, testando-se modelos de primeiro e segundo grau. Na escolha dos modelos utilizaram-se os critérios de significância do teste $\mathrm{F}$ para o modelo ajustado e maior coeficiente de determinação ente os modelos significativos. Quando houve interação significativa entre variedades e frações de lixiviação realizou-se o desdobramento das variáveis dentro de cada fator.

\section{RESULTADOS E DISCUSSÃO}

O resumo da análise de variância é apresentado na Tabela 3, onde observa-se interação significativa entre os fatores variedades e frações de lixiviação para todas as variáveis avaliadas. 
Tabela 3. Resumo da análise de variância com valores de F para os teores foliares de micronutrientes em plantas de sorgo forrageiro.

\begin{tabular}{lcccc}
\hline Fonte de variação & $\mathrm{Cu}$ & $\mathrm{Fe}$ & $\mathrm{Mn}$ & $\mathrm{Zn}$ \\
\cline { 2 - 5 } Bloco & $3,914^{*}$ & $2,687^{\mathrm{ns}}$ & $3,273^{\mathrm{ns}}$ & $2,823^{\mathrm{ns}}$ \\
Fração de lixiviação & $13,317^{* *}$ & $1,676^{\mathrm{ns}}$ & $42,763^{* *}$ & $21,059^{* *}$ \\
Variedade & $36,434^{* *}$ & $0,33^{\text {ns }}$ & $5,69^{* *}$ & $5,025^{*}$ \\
Fração vs Variedade & $4,418^{* *}$ & $2,665^{*}$ & $2,526^{*}$ & $2,612^{*}$ \\
CV 1 (\%) & 12,86 & 11,01 & 19,33 & 20,8 \\
CV 2 (\%) & 15,24 & 14,14 & 28,51 & 37,3 \\
\hline
\end{tabular}

ns= não significativo; *= significativo a 0,05 de probabilidade; **= significativo a 0,01 de probabilidade.

Para os teores foliares de $\mathrm{Cu}$, apenas as variedades Volumax e F305 apresentaram regressões significativa, com ajuste ao modelo linear. Para as duas variedades observam-se acréscimos nos teores foliares de $\mathrm{Cu}$ com o aumento da fração de lixiviação (FL) (Figura 1). Resultado este semelhante ao observado por Sousa et al. (2010) que, ao avaliarem o efeito da salinidade na absorção de micronutrientes na cultura do milho, verificaram que a salinidade provocou um desbalanço dos teores deste íon nas plantas.

Os teores foliares de $\mathrm{Cu}$ observados em todas as variedades neste estudo estão dentro dos limites considerados normais por Prado (2008) para a cultura do sorgo, que variam de $5-20 \mathrm{mg} \mathrm{kg}^{-1}$.

Apenas a variedade F305 apresentou ajuste significativo dos dados aos modelos de regressão testados para os teores foliares de Fe (Figura 1B) e de Mn (Figura 1C). Em ambos os casos, observou-se tendência à redução dos teores desses micronutrientes em função do aumento das frações de lixiviação (FL). Pode-se observar teores de Fe acima do limite superior recomendado por Prado (2008), $100 \mathrm{mg} \mathrm{kg}^{-1}$, em todas as FL testadas neste estudo. Apesar da redução dos teores de $\mathrm{Mn}$, todas as variedades apresentam valores considerados adequados para a cultura do sorgo, 10-190 $\mathrm{mg} \mathrm{kg}^{-1}$, (PRADO, 2008).

Já para o micronutriente zinco (Zn), observou-se ajuste de modelos de regressão significativos para as variedades F305 e Sudão (Figura 1D), apresentando os teores decréscimos lineares nos seus valores com o aumento da FL. No entanto, todas as variedades apresentam teores foliares de $\mathrm{Zn}$ considerados adequados para a cultura do sorgo, variando de 15 a 50 mg kg-1 (PRADO, 2008).

A faixa de $\mathrm{pH}$ do solo favorável à disponibilidade desses micronutrientes varia de 4,0 a 6,5 (SOUSA et al., 2007). É possível que com o uso da irrigação com água residuária de piscicultura, considerando seu $\mathrm{pH}$ e características físico-químicas do solo, tenha proporcionado elevação do $\mathrm{pH}$ do solo ao longo do ciclo de cultivo, tendo em vista que o pH da água de irrigação utilizada (Tabela 2) é superior ao $\mathrm{pH}$ do solo cultivado (Tabela 1).

Para os micronutrientes Fe, Mn e Zn, devido sua maior mobilidade, em solos com textura franca e com baixa CTC há maior facilidade de perda por lixiviação, principalmente após chuvas ou irrigações pesadas. Simões et al. (2016) verificaram uma maior distribuição dos íons do solo com o aumento da fração de lixiviação no mesmo solo cultivado com beterraba. Com a aplicação das frações há uma lixiviação dos íons presentes na rizosfera, diminuindo assim a disponibilidade destes para a planta. Comportamento contrário foi observado para o $\mathrm{Cu}$ devido a sua baixa mobilidade no solo (CASALI et al., 2008).

Apesar da redução dos teores de Fe, $\mathrm{Mn}$ e Zn, os mesmos se encontram dentro do limite sugerido por Prado (2008), sendo que a aplicação de frações de lixiviação maior que as testadas neste estudo pode provocar deficiência destes íons. 
•Volumax OF305 口Sudão
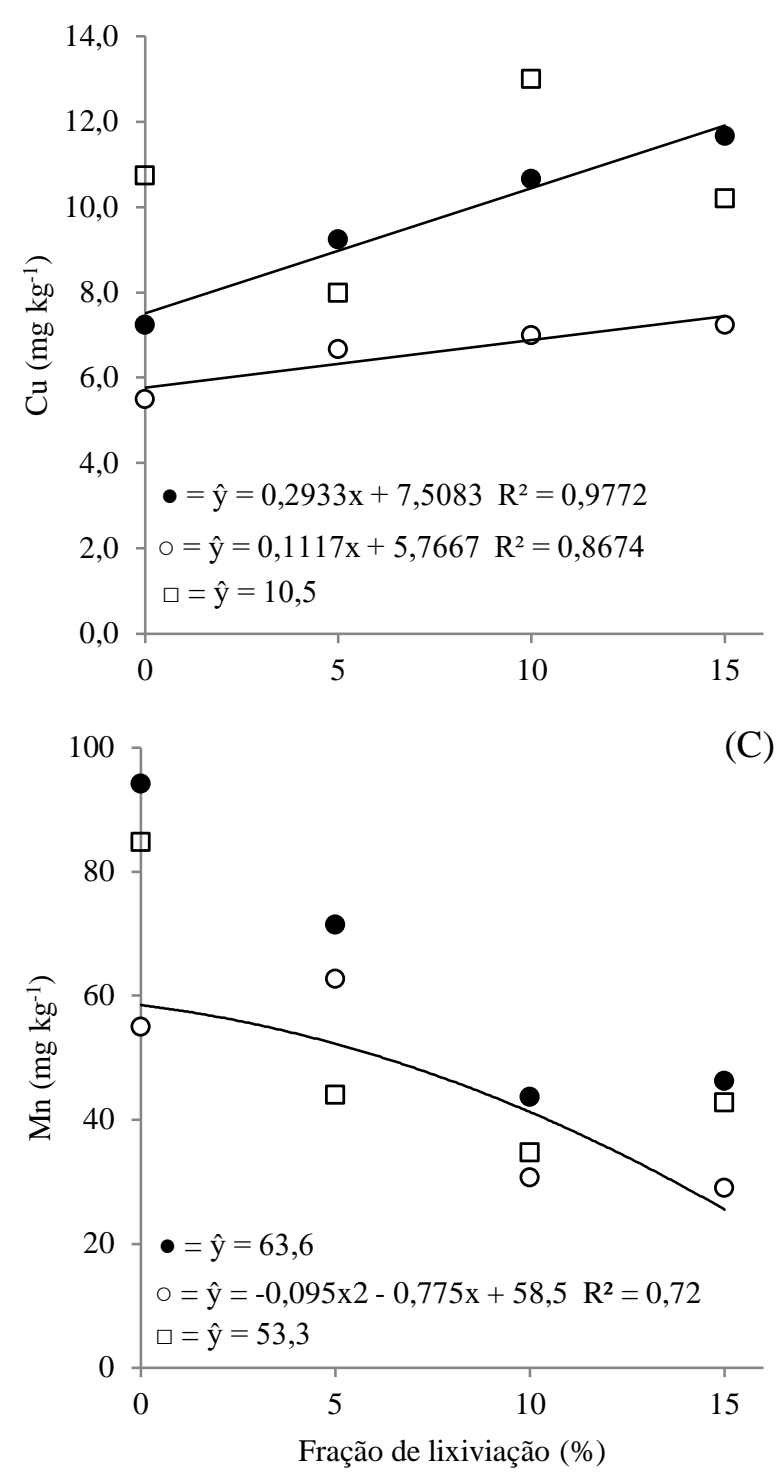

(A)
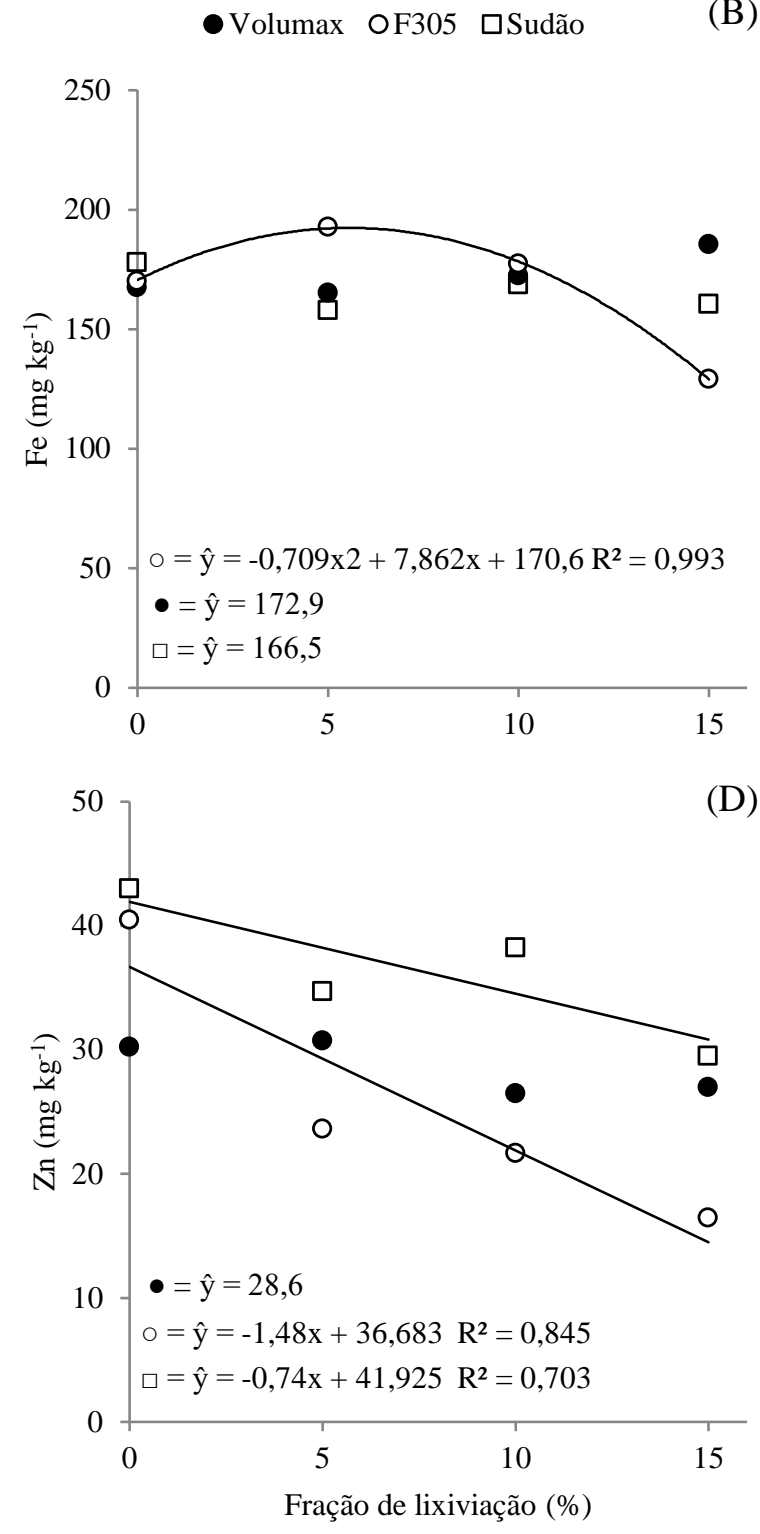

Figura 1. Teores de cobre (A), ferro (B), manganês (C) e zinco (D) no tecido foliar de plantas de sorgo forrageiro das variedades Volumax, F305 e Sudão, submetido a diferentes frações de lixiviação com efluente salino da piscicultura.

Não houve ajuste significativo para a variedade Sudão nos teores de $\mathrm{Cu}$, Fe e Mn, os quais apresentaram médias 10,5; 166,5 e 53,3 $\mathrm{g} \mathrm{kg}^{-1}$, respectivamente. Para a variedade Volumax não houve ajuste para os teores de Fe, Mn e Zn, com 172,9; 63,9 e 28,9 $\mathrm{g} \mathrm{kg}^{-1}$, respectivamente.

Observa-se um aumento no teor de $\mathrm{Cu}$ nos tecidos vegetais avaliados com o aumento da fração da lixiviação. Se tratando de estresses abióticos o mesmo está associado a superóxido dismutase, enzima que atua em conjunto com a catalase para destoxificar espécies oxidantes produzidas como subproduto do estresse salino (EPSTEIN; BLOOM, 2004). Assim, um aumento nestes valores pode ter efeitos positivos na supressão deste estresse.

O Mn atua no fotossistema II na oxidação da molécula da água, além de constituir moléculas de superóxido dismutase, enzima atuante no mecanismo e proteção contra radicais livres. A sua deficiência provoca significativos prejuízos nas reações de hidrólise da água, fotofosforilação, fixação do $\mathrm{CO}_{2}$ e redução do nitrato e nitrito, cujo doador de elétrons 

EFLUENTE SALINO DE PISCICULTURA

em ambos os processos é a ferredoxina (ALMEIDA et al., 2014). Apesar de não ter sido verificado deficiência deste íon nas plantas avaliadas neste trabalho, a aplicação de FL superiores às testadas neste estudo pode provocar a deficiência de manganês em plantas de sorgo.

\section{CONCLUSÕES}

O uso de irrigação com efluente salino de piscicultura com fração de lixiviação de até $15 \%$ alteraram os teores foliares de $\mathrm{Cu}, \mathrm{Zn}$, Fe e $\mathrm{Mn}$ em plantas de sorgo forrageiro, mas não causaram excessos ou deficiências dos mesmos.

\section{REFERÊNCIAS BIBLIOGRÁFICAS}

ALMEIDA, E. I. B.; NÓBREGA, G. N.; CORRÊA, M. C. M.; PINHEIRO, E. A. R.; ARAÚJO, N. A. Crescimento e marcha de absorção de micronutrientes para a cultivar de melancia Crimson Sweet. RevistaAgro@mbiente On-line, v.8, n.1, p.74-80, 2014.

BOTELHO, P. R. F.; PIRES, D. A. A.; SALES, E. C. J.; ROCHA JUNIOR, V. R.; REIS, S. T. Avaliação de genótipos de sorgo em primeiro corte e rebrota para produção de silagem. Revista Brasileira de Milho e Sorgo, v.9, n.3, p. 287-297, 2010.

CARMO, D. L.; NANNETTI, D. C.; LACERDA, T. M.; NANNETTI, A. N.; SANTOS, D. J. E. Micronutrientes em solo e folha de cafeeiro sob sistema agroflorestal no Sul de Minas Gerais. Coffee Science, v. 7, n. 1, p. 76-83, 2012.

CASALI, C. A.; MOTERLE, D. F.; RHEINHEIMER, D. S.; BRUNETTO, G.; CORCINI, A. L. M.; KAMINSKI, J. MELO, G. W. B. Formas e dessorção de cobre em solos cultivados com videira na Serra Gaúcha do Rio Grande do Sul.
Revista Brasileira de Ciência do Solo, v.32, n.4, p. 1479-1487. 2008.

CAVALCANTI, F. J. DE A. Recomendações de adubação para o Estado de Pernambuco. 2 $2^{\mathrm{a}}$ Apr. 3.ed., Recife: IPA, 2008. 212p.

DIAS, N. S.; BLANCO, F. F. Efeitos dos sais no solo e na planta. HANS RAJ GHEYI, NILDO DA SILVA DIAS, CLAUDIVAN FEITOSA DE LACERDA (Editores). Manejo da salinidade na agricultura: Estudo básico e aplicados. Fortaleza, INCT Sal, 2010. p. 129-140.

EPSTEIN, E.; BLOOM, A. J. Nutrição mineral de plantas: princípios e perspectivas. 2 ed. Londrina: Andrei, 2004, $403 \mathrm{p}$.

EMPRESA BRASILEIRA DE PESQUISA AGROPECUÁRIA - EMBRAPA. Sistema brasileiro de classificação de solos. 3.ed. Brasília, 2013. 353p.

EMBRAPA. Manual de análises químicas de solos, plantas e fertilizantes. Embrapa Informação Tecnológica. 2. ed. Brasília, 2009. 627p.

GRATTAN, S. R.; GRIEVE, C. M. Salinity-mineral nutrient relations in horticultural crops. Scientia Horticulturae, v.78, p.127-157,1999.

GURGEL, M. T.; GHEYI, H. R.; OLIVEIRA, F. H. T.; FERNANDES, P. D.; SILVA, F. V. Nutrição de cultivares de meloeiro irrigadas com águas de baixa e alta salinidade. Revista Caatinga, v.21, n.5, p.36-43, 2008.

LOPES, A.S. - Micronutrientes: filosofias de aplicação, fontes, eficiência agronômica e preparo de fertilizantes In: Simpósio sobre Micronutrientes na Agricultura Jaboticabal -1988 - Anais... Eds. Ferreira, 
M. E. ; Cruz, M. C. P. - Piracicaba: POTAFOS/CNPq, 1991.

NEVES, O.S.C.; CARVALHO, J.G.; RODRIGUES, C.R. Crescimento e nutrição mineral de mudas de umbuzeiro (Spondias tuberosa Arr. Cam.) submetidas a níveis de salinidade em solução nutritiva. Ciência e. Agrotecnologia, v.28, n.1, p.997-1006, 2004.

PRADO, R. de M. Nutrição de Plantas. 1. ed. São Paulo: UNESP/FUNESP, 2008. 408 p.

SANTOS, R. D.; PEREIRA, L. G. R.; NEVES, A. L. A.; RODRIGUES, J. A. S.; COSTA, C. T. F.; OLIVEIRA, G. F. Agronomic characteristics of forage sorghum cultivars for silage production in the lower middle San Francisco Valley. Acta Scientiarum. Animal Sciences, v.35, n. 1, p. 13-19, 2013.
SIMÕES, W. L.; YURI, J. E.; GUIMARÃES, M. J. M.; SANTOS, J. E.; ARAÚJO, E. F. J.Beet cultivation with saline effluent from fish farming. Revista Brasileira de Engenharia Agrícola e Ambiental, v. 20, n. 1, p. 62-66, 2016.

SOUSA, G. G.; LACERDA, C. F.; SILVA, G. L.; FREITAS, A. S.; CAVALCANTE, L. F.; SOUSA, C. H. C. Acumulação de biomassa, teores e extração de micronutrientes em plantas de milho irrigadas com águas salinas. Agropecuária Técnica, v. 31, n. 2, p. 1-10, 2010.

SOUZA, D.M.G.; MIRANDA, L.N. \& OLIVEIRA, S.A. Acidez do solo e sua correção. In: NOVAIS, R.F.; ALVAREZ V, V.H.; BARROS, N.F.; FONTES, R.L.F.; CANTARUTTI, R.B. \& NEVES, J.C.L. Fertilidade do solo. Viçosa, MG, Sociedade Brasileira de Ciência do Solo, 2007. p.205-274. 